International Journal of Advanced Academic Research (Sciences, Technology and Engineering) | ISSN: 2488-9849

Journal DOI: 10.46654/ij.24889849

Vol. 6, Issue 8 (August, 2020)|www.ijaar.org

Article DOI: 10.46654/ij.24889849.e6814

\title{
EROSION - CORROSION BEHAVIOUR OF ANTIMONY MODIFIED CARBIDIC AUSTEMPERED DUCTILE IRON USING A DESIGNED SLURRY POT
}

\author{
A. O. Alao ${ }^{1}$, A. Barnabas ${ }^{2}$, S.A., Shittu ${ }^{2}, J_{\text {. Ogbodo }}{ }^{3}$ and Dongo $I^{3}$. \\ ${ }^{1}$ Department of Foundry Engineering, Federal Polytechnic, Idah, Kogi State, Nigeria. \\ ${ }^{2}$ Department of Metallurgical and Materials Engineering, Federal University of Technology, Akure, Ondo State, \\ Nigeria. \\ ${ }^{3}$ Department of Metallurgy and Materials Engineering, Kogi State Polytechnic, Lokoja, Kogi State, Nigeria. \\ Corresponding author: sweetdamse108@gmail.com, barnabelad0110@ gmail.com.
}

\begin{abstract}
This study involves erosion corrosion behaviour of CADI using slurry pot containing mixture of silica sand and $3.5 \mathrm{wt}$. \% $\mathrm{NaCl}$ solutions. The slurry pot was controlled by a horse power electric motor which caused the rotation of the stirrer, leading to agitation of the mixture. $110 \mathrm{~V}$ resulting in rotational speed of $1100 \mathrm{rpm}$ was applied for the erosion-corrosion test. Hardness values obtained from the un-heat treated samples ranged from 30 to $43.8 \mathrm{HRc}$. While that of heat treated samples ranged from 28.5 to $55.2 \mathrm{HRc}$. Erosion corrosion rates of $6.8 \mathrm{E}^{-4}$ to $8.3 \mathrm{E}^{-}$ ${ }^{4} \mathrm{~g} / \mathrm{cm}^{2} / \mathrm{hr}$ were obtained for the un-heat treated samples while the corrosion rates of the heat treated samples ranging $6.2 \mathrm{E}-2$ to $3.8 E-4 \mathrm{~g} / \mathrm{cm}^{2} / \mathrm{hr}$ were recorded. It was observed that as hardness increased, there was reduction in weight loss index. For the un-heat treated samples, sample with $0.5 \mathrm{wt}$. \% Sb had the least erosion corrosion rate of $8.3 \mathrm{E}-4 \mathrm{~g} / \mathrm{cm}^{2} / \mathrm{hr}$, among the heat treated samples; sample with $0.3 \mathrm{wt}$. \% of Sb had the least erosion corrosion rate of 7E$4 \mathrm{~g} / \mathrm{cm}^{2} / \mathrm{hr}$. It was concluded that Sb addition improves erosion-corrosion resistance of CADI and also, the heat treatment improved the resistance of carbidic ductile iron to erosion-corrosion.
\end{abstract}

Keyword: Antimony, CADI, $\mathrm{NaCl}$ solution, Erosion-corrosion. 


\section{INTRODUCTION}

Erosion corrosion is a complex material degradation mechanism, arising from both chemical and mechanical interactions [1, 2]. Mining, Agriculture, hydropower and oilfield environments are among the areas where this materials degradation mechanism is prevalent $[3,4]$.

Slurry erosion pot is one of the numerous methods that can be used to study erosion corrosion. The slurry pot has an advantage of a simple arrangement for potentiometric control of the specimens as well as ability to attain higher rotational speed. This experimental rig is also recommended for the understanding of the mechanism of erosion- corrosion interaction for dilute slurry $[5,6]$. The presence of retained austenite in such matrix also makes such alloy strain hardenable due to the metastable phase of austenite (martensite)[7-10]. Many attempts have been made in the past to relate the volume fraction of martensite in such alloy to its tribological behavior [11-13].

However, little information is available to correlate the microstructure properties of CADI with the slurry erosion properties [14], though some claimed it's insignificant. High hardness has been reported to result in low erosion rate for ductile metals [15]. This research is an attempt to expand the data base on the erosion - corrosion characteristics of CADI.

\section{MATERIALS AND METHODS}

Equipment used was slurry pot which outer shell pot is made of mild steel while the inner part is made of high density polyethylene; for the purpose of reducing corrosion of the inner wall. Inner diameter of the pot has a depth of $35 \mathrm{~cm}$ and diameter of 29 and total capacity was evaluated to be 23 litres in volume. The sample holder was made of Perspex with a centre hole of diameter 2 $\mathrm{cm}$ to fit the shaft. Material used were heat treated and unheat treated samples of Sb-CADI with varied antimony $(\mathrm{Sb})$ content of 0 wt. \%, 0.096 wt. \%, 0.192 wt. \%, 0.288 wt. \%, 0.384 wt. \% and 0.48 wt. $\%$.

\subsection{Experimentation of Erosion - corrosion}

Erosion - corrosion test was carried out using the designed slurry pot. The test solution used in this study contains 3.5 wt. $\% \mathrm{NaCl}$ and $500 \mathrm{mg} / \mathrm{L}$ silica sand with particle distribution in accordance with Aribo et al. [16]. Prior to immersion, the test samples were grounded to a surface finish of 1200 grit using silicon carbide paper, polished with 15 um diamond paste, degreased, washed in distilled water and dried in air. The slurry pot was operated at an average speed of 1100. Each experiment was performed for 1 hour and the weights before and after the experiment were measured and recorded. Six samples were tested and their results obtained were recorded. The erosion- corrosion rate was calculated using equation 1 ;

Erosion - corrosion rate $=\frac{\text { Weight loss }}{\text { Surface area }\left(\mathrm{cm}^{2}\right) \times \text { time }(\mathrm{hr})}$ 


\subsection{Hardness Test}

The hardness test for the produced samples was conducted using Digital Rockwell hardness tester on scale C, in accordance with ASTM E18-08 [17] (standard test method for Rockwell hardness of metallic materials). The hardness value was then displayed on the machine. Four point's hardness values were measured and average of the four measurements was taken.

\section{Result and Discussion}

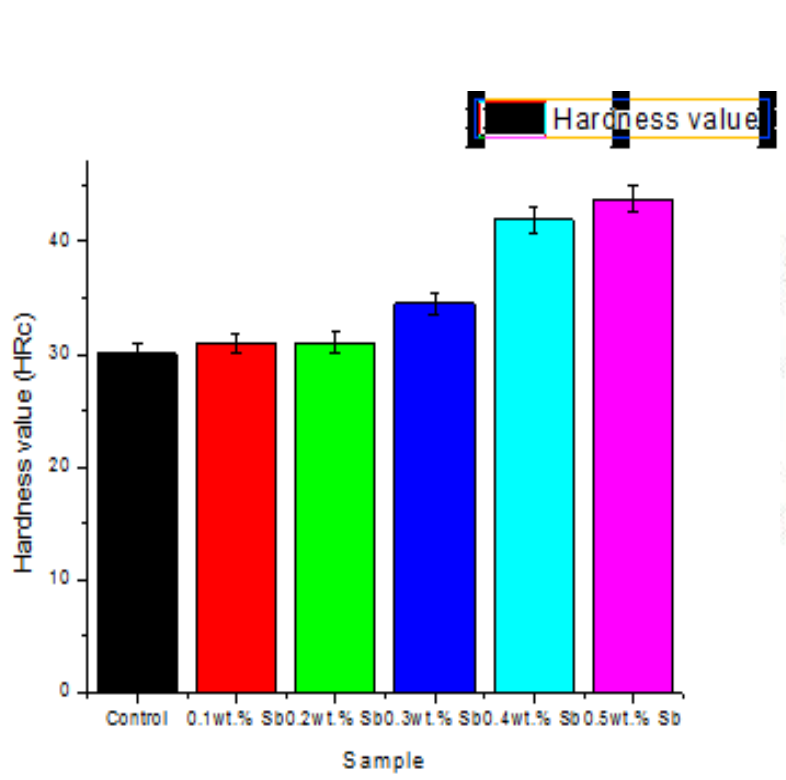

(a)

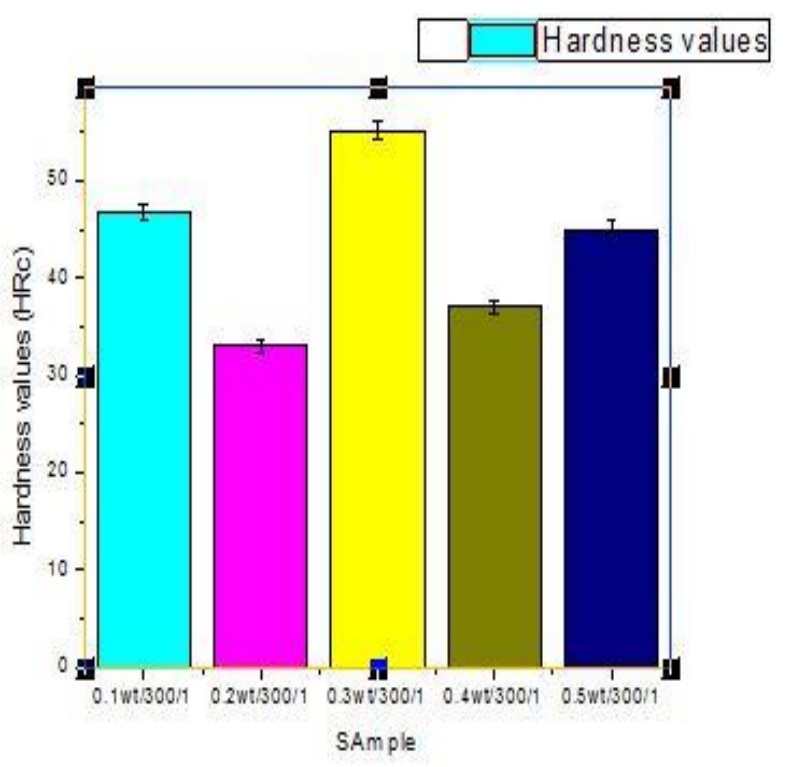

(b)

Fig 1: Variation of the hardness value of the (a) heat treated and (b) unheat treated CADI

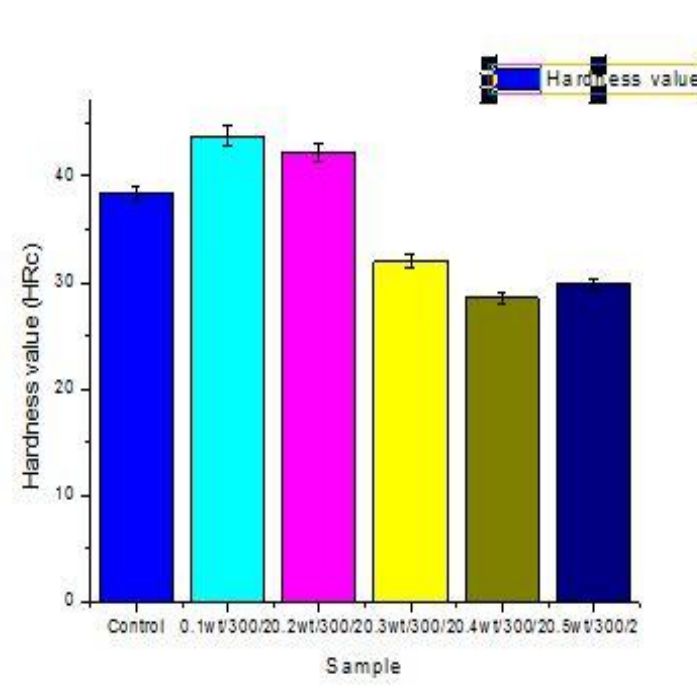

(a)

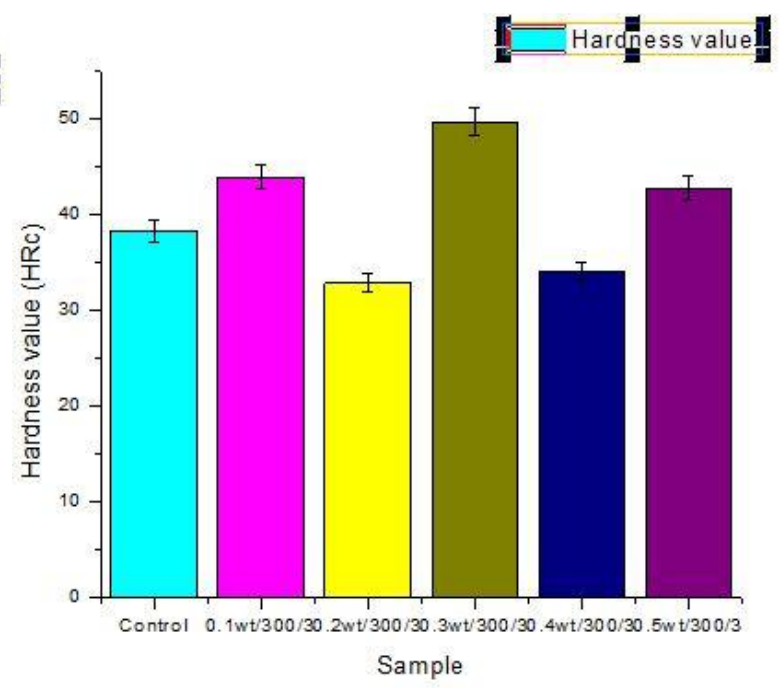

(b)

Fig 2: variation of the hardness value of the (a) heat treated and (b) unheat treated CADI 

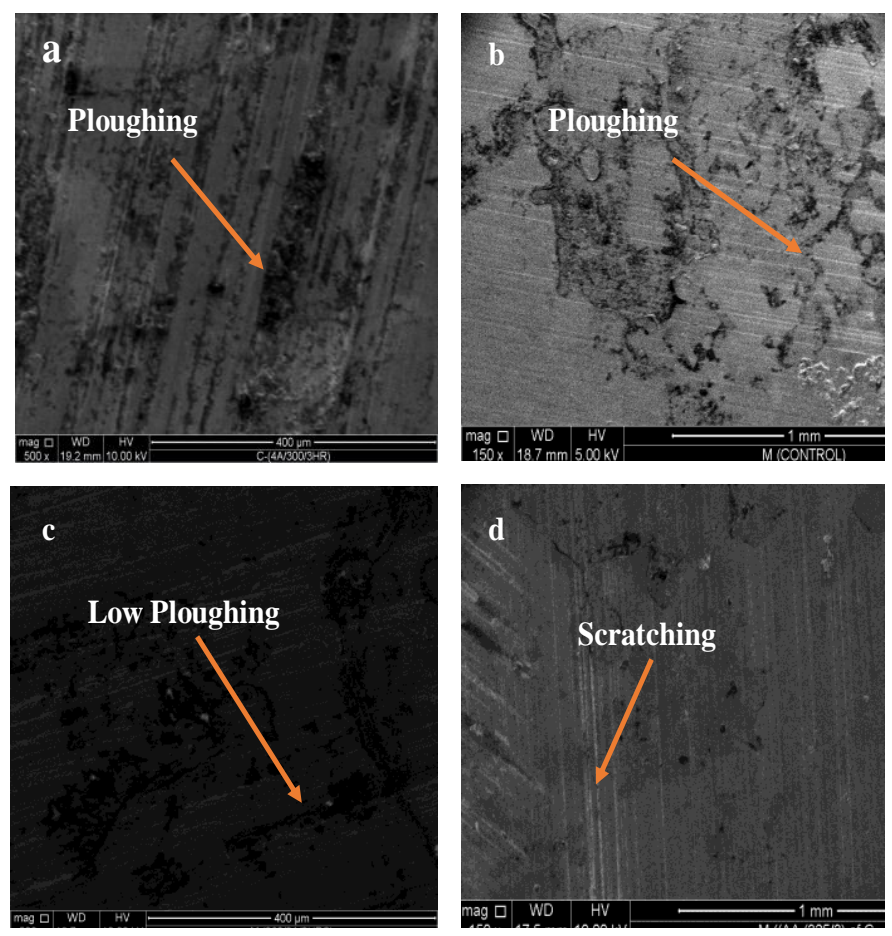

Fig. 3: Optical micro-image of samples exposed to erosion-corrosion showing (a) (b) ploughing, (c) low ploughing and (d) scratching.

\section{Erosion - corrosion Properties}

Figs. 1 and 2 also showed that increase in hardness of the CADI resulted in higher resistance to erosion - corrosion. It will be recalled that higher hardness was recorded. The results of the erosion- corrosion tests performed on Sb - CADI samples are as shown in Figs. $4 \mathrm{a}$ and $4 \mathrm{~b}$. Good repeatability is seen in all the experiments conducted as shown by the deviations from the mean values illustrated by the error bars in Fig. 4. 


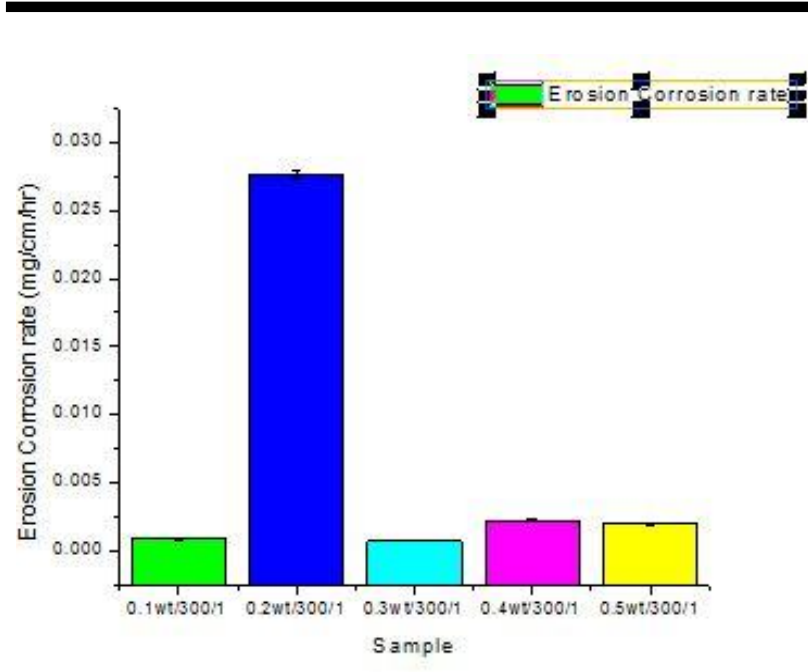

(a)

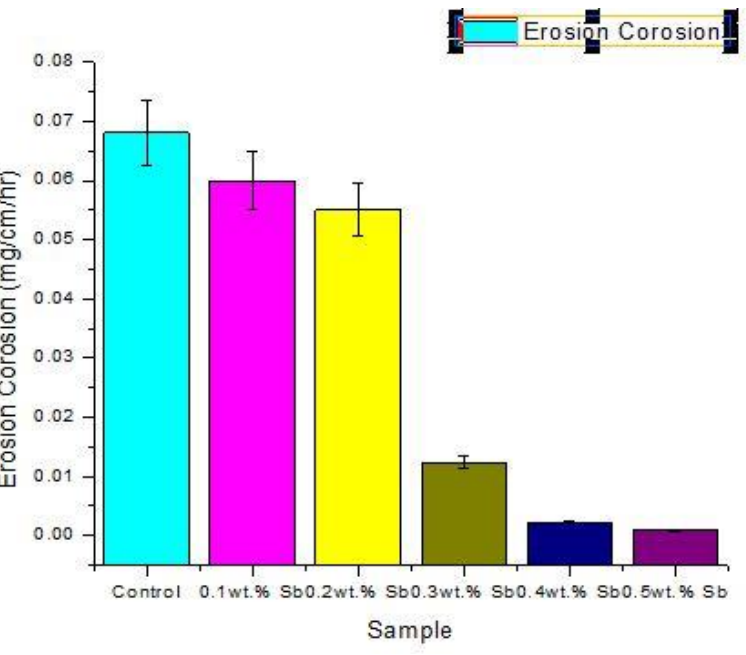

(b)

Fig 4: Variation of the hardness value of the heat treated and unheated treated CADI

\section{Relationship between the Microstructure and Erosion - corrosion Resistance}

There is a direct relationship between carbide size and the erosion corrosion resistance of both unheated treated and heat treated CADI. As the carbide size reduces from coarse to granular, as a result of $\mathrm{Sb}$ modification of the CADI, erosion corrosion resistance increases. In the heat treated samples, ausferrite formed led to further improvement in the erosion corrosion resistance. Hence, $\mathrm{Sb}$ addition improves erosion-corrosion resistance of CADI and also, the heat treatment improved the resistance of carbidic ductile iron to erosion-corrosion.

This is in line with previous studies which reported the effects of phase's volume fractions in assessing the mechanical properties of ferrous metals [18]. The results obtained in this study tend to be more supportive of the work of Tekeli and Gural [19].

\section{Degradation Mechanism}

Degradation mechanism shows both scratching and ploughing (Fig. 3a, b, c and d). Scratches and ploughing from the sand is expected at that rotational speed and high volume fraction of sand particles. This is a classical mode of degradation in a slurry erosion. There is effect of the corrosive medium on the heat treated CADI. With general and localized corrosion seen on the steel surface. It can therefore be deduced that there is a form of synergy between erosion and corrosion although the extent has not been quantified in this study.

\section{Conclusion}

Results on heat treated and un-heat treated CADI samples show different hardness values. It was observed from the results that higher hardness value resulted in higher erosion corrosion resistance while higher slurry speed resulted in higher material loss due to erosion corrosion. 
International Journal of Advanced Academic Research (Sciences, Technology and Engineering) | ISSN: 2488-9849

Journal DOI: 10.46654/ij.24889849

Vol. 6, Issue 8 (August, 2020)| www.ijaar.org

Article DOI: 10.46654/ij.24889849.e6814

Degradation of the alloy combines both erosion and corrosion with ploughing and pitting dominating the degradation mechanism.

\section{Model Summary}

\section{Regression Equation}

Erosion corrosion $\left(\mathrm{g} / \mathrm{cm}^{2} \mathrm{hr}\right.$. $)=0.0554-0.1341$ (wt. \% antimony content)

$\mathrm{S}=2.3416, \mathrm{R}^{2}=0.88$

\section{Regression Equation}

Hardness $(\mathrm{HRc})=27.82+30.66$ (Erosion corrosion rate $\left(\left(\mathrm{g} / \mathrm{cm}^{2} \mathrm{hr}.\right)\right)$

$\mathrm{S}=0.0139, \mathrm{R}^{2}=0.80$

\section{Regression Equation}

Erosion corrosion rate $\left(\mathrm{g} / \mathrm{cm}^{2} \mathrm{hr}.\right)=0.0554-0.1341$ Hardness $(\mathrm{HRc})$ 


\section{References}

[1] Wood Robert, (2006). Erosion-corrosion interactions and their effect on marine and offshore materials. J. of Wear, vol 261, pp. 1012-1023. 10.1016/j.wear.2006.03.033

[2] Stack, Margaret and Jana, B. D. and Abdelrahman, Shehab, (2011). Models and mechanisms of erosion-corrosion in metals. J. of Tribocorrosion of Passive Metals and Coatings, pp. 153-186. 10.1016/B978-1-84569-966-6.50006-3

[3] CapcisLimited. Review of corrosion management for offshore oil and gas processing. Offshore Technology Report, 2001/044, HSE Offshore Technology, ISBN 071762096 4, 2001.

[4] Oberndorfer, M., K. Thayer and W. Havlik. Corrosion control in the oil and gas production- 5 successful case histories. In: NACE corrosion conference, Paper No. 07317, Nashville, Tennessee. NACE International, 2007.

[5] ojala, Niko and Valtonen, Kati and Paivi, Kivikyto-Reponen and Vuorinen, Petri and Kuokkala, Veli-Tapani, (2015). High speed slurry-pot erosion wear testing with large abrasive particles. Tribology: Finnish Journal of Tribology, 33, pp. 36-44

[6] Tian, B. and Cheng, Y., (2008). Electrochemical Corrosion behaviour of X-65 steel in the simulated oil sand slurry. I: Effects of hydrodynamic condition. J. Corrosion ScienceCORROS SCI, 50, pp. 773-779. 10.1016/j.corsci.2007.11.008

[7] Kelly, R.G., J.R. Scully, D.W. ShoesmithAnd G.B. Rudolph. Electrochemical techniques in corrosion science and engineering. New York: Marcel Dekker Inc, ISBN 0-82479917-8, 2003.

[8] Hossain, Rumana and Pahlevani, Farshid and Quadir, M. D and Sahajwalla, Veena, (2016). Stability of retained austenite in high carbon steel under compressive stress: and investigation from macro to nano scale. Scientific reports. 6. 10.1038/srep34958.

[9] Newman, R.C. $2001 \mathrm{Wr}$ Whitney award lecture: Understanding the corrosion of stainless steel. Corrosion Science, 2001, 57(12), pp.1030-1041

[10] Gupta S, Khandelwal A, Ghose A. K, Chakrabarty I. (2016). Surry Erosion Behaviour of Destabilized and Deep Cryogenically Treated $\mathrm{Cr}-\mathrm{Mn}-\mathrm{Cu}$ White Cast Irons, J. of Tribology in Industry, 38(4), pp. 486-495.

[11] Zhang, Jiecen, and Di, Hongshuang and Deng, Youggang and Misra, R,D.K., (2015). Effect of Martensite Morphology and Volume Fraction on strain Hardening and Fracture behaviour of Martensite-Ferrite Dual phase steel. J. Materials Science and Engineering: A. 627. 10.1016/j.msea.2015.01.006

[12] Roy Chowdhury S. K., Malhotra K., Padmawar H., (2013). Effect of Contact Temperature Rise During Sliding on the Wear Resistance of TiNi Shape Memory Alloys, J. Tribology in Industry, 35(1), pp. 84-94.

[13] Rajahram, S.S., T.J. Harvey, J.C. Walker, S.C. Wang And R.J.K. Wood. Investigation of erosion-corrosion mechanisms of UNS S31603 using FIB and TEM. Tribology International, 2012, 46(1), pp.161-173.

[14] Balan, K.P and Reddy, A. Venugopal and Joshi, Vydehi and Sundararajan, Govindan, (1991). The Influence of Microstructure on the Erosion Behavior of Cast Iron. Wear. 145(2), pp. 283-296. 10.1016/0043-1648(91)90136-1

[15] Malik, Jahanzaib and Toor, Ihsan and Ahmed, Wael and Gasem, Zuhair and Habib, M. A. and Ben-Mansour, Rached and Badr, H. (2004). Evaluating the Effect of Hardness on 
Erosion Characteristics of Aluminium and Steels. J. of materials Engineering and Performance . 23(6), 10.1007/s11665-014-1004-X

[16] Aribo S., Adedapo I., Nwogwugwu C., Olaniran O., Olaseinde A., Ige O., Olubambi P. A., (2018). Erosion -Corrosion Behaviour of Dual Phase Medium Carbon Steel using a Designed Slurry Pot, 40(2), pp. 239-246, 10.24874/ti.2018.40.02.07.

[17] ASTM E18-20, Stanadrd Test Methods for Rockwell Hardness for Metallic Materials, ASTM International, West Conshohocken, PA, 2020.

[18] Razali, N., and Hamzah E., and Norliana S., and Irwan, M. A., (2011). Study on the Effect of Volume Fraction of Dual Phase Steel to Corrosion Behaviour and Hardness. World Accademy of Science, Engineering and Technology. 50, pp. 564-567. 